\title{
Characterization of residual stresses in heat treated Ti-6Al-4V forgings by machining induced distortion
}

\author{
B. Regener ${ }^{1, a}$, C. Krempaszky ${ }^{1}$, and E. Werner ${ }^{2}$ \\ 1 Christian Doppler Laboratory of Material Mechanics of High Performance Alloys, Lehrstuhl für \\ Werkstoffkunde und Werkstoffmechanik, Technische Universität München \\ ${ }^{2}$ Lehrstuhl für Werkstoffkunde und Werkstoffmechanik, Technische Universität München
}

\section{Abstract}

To provide a solid base for improved material exploitation in dimensioning calculations it is necessary to determine the stress state in the part prior to service loading. In order to achieve higher material strength at elevated temperatures, the surface temperature gradient with respect to time has to be sufficiently high during heat treatment. This results in non-negligable residual stresses that can reduce the allowable load level upon which yielding occurs. For titanium alloys there are two common heat treatments, namely solution treatment and mill annealing. The latter one is the method of choice within the presented project. Mill annealing is utilized in order to significantly reduce the residual stresses in the parts without loosing much of the improved strength at elevated temperatures. Quantification of residual stresses is done by solving an inverse problem. From the measurement of distortion, induced by dividing the investigated part, the residual stress state can be calculated via analytical modeling or correlation with finite element models. To assure a minimum perturbation of the residual stress state during specimen production, dividing of the part is accomplished by electric discharge machining.

The parts of interest are v-shaped prisms with a length of approximatly $450 \mathrm{~mm}$ and a thickness in the cross sectional area from about $20 \mathrm{~mm}$ to $45 \mathrm{~mm}$. Figure 1(a) shows the forged part and 1(b) the dimensions of the cross section in millimeters as well as the material properties considered in the finite element model. The heat exchange between the part and the environment is modelled as heat transfer by convection superimposed with heat radiation. Since the parts are exposed to air during forging and heat treatment, the surface develops a strongly adhesive oxide layer, the so called alpha-case. After forging the parts are cooled in air and heat treated at a temperature of $720^{\circ} \mathrm{C}$ for a duration of $120 \mathrm{~min}$. Subsequent air cooling and removing the alpha-case by shot peening and chemical treatment in a mixture of nitric and hydroflouric acid finishes the processing.

The residual stress state in the parts is quantified through correlation of results obtained by finite element simulations and high precision deflection experiments. Experimental measuring errors are minimized by using the capability of the wire cutting machine to measure locations on the specimens with respect to the fixed machine coordinate system. A sophisticated design of cutting operations allows an analysis of the part without removing the fixture and hence makes it possible to achieve a very high accuracy of the displacement measurements of about $4 \mu \mathrm{m}$.

The quality of the obtained results also depends on the finite element models describing the mechanics of the experimental investigations as precise as possible. Since numerical modeling of shot peening and chemical milling is rather complicated, the whole processing route of the shapes is simplified assuming that the individual contribution of all process steps to the residual stress state can be described by virtual heat transfer coefficients. The overall virtual heat transfer coefficient for the whole processing route is calculated from the linear superposition of the individual heat transfer coefficients for each

\footnotetext{
${ }^{a}$ e-mail: regener @km now tum de
} 


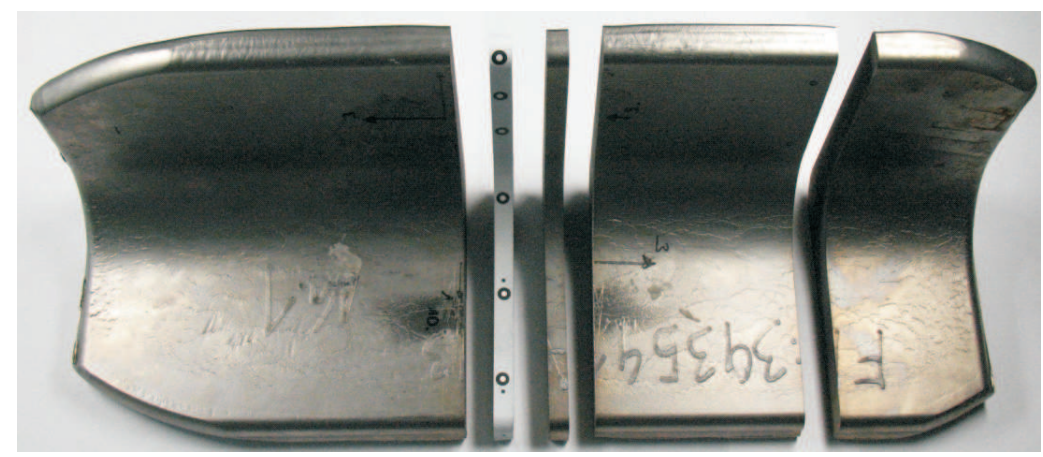

(a)

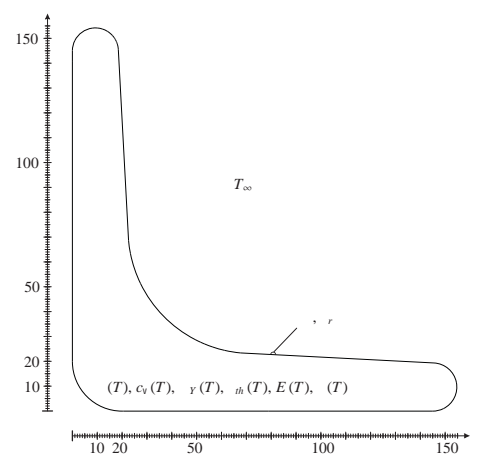

(b)

Fig. 1. (a) Divided Ti-6Al-4V v-shaped forging. Specimens are taken from areas away from the end plane. (b) Schematic sketch of the two-dimensional finite element model.

processing step. Detailed analysis of the obtained overall virtual heat transfer coefficients in comparison with experimentally obtained ones shows, that other processing steps besides the heat treatment considerably influence the residual stress state. In order to make the conducted simulation scheme applicable in practise, advanced finite element modeling techniques are developed. The experimentally derived deflection curves are correlated to the finite element results via a least square fit. 